\section{AUTHORS' REPLY:}

\section{Dear Dr Winger:}

We read with interest your comments regarding our $J A T$ manuscript on fluid balance and electrolyte replenishment during prolonged exercise. In fact, we are pleased that our data have provided stimulus for further inquiry, even if alternative interpretations were drawn. However, we have some major concerns about your approach in the field.

1. In our manuscript, we did not make any suggestion at all on the fluid that should be replenished during exercise. This is an interesting topic that has caused debate among groups researching fluid balance. In any case, there is certainly no need to distort meanings of physiologic terms such as hydration status, fluid balance, overhydration, and dehydration. Loss of body fluids can be considered a state of dehydration and, similarly, excess body fluids as a state of overhydration. We cannot understand why matching fluid loss with fluid intake might be considered overhydration.

2. Thirst is indeed an insufficient means to replace sweat fluid loss during exercise. This phenomenon has been demonstrated in all relative research papers, including those that you have mentioned. Replenishing 20\%$70 \%$ of sweat loss when drinking ad libitum cannot be considered sufficient, as it could induce dehydration above the critical level of $2 \%$ of body weight. Such levels of dehydration have consistently been found to hamper endurance performance and predispose the athlete to heat illnesses. ${ }^{1-3}$ In fact, many authors ${ }^{4-6}$ have shown that under specific conditions, athletic performance may deteriorate even at lower levels of dehydration.

3. Exercise-induced weight loss is always accompanied by alterations in fluid dynamics and losses from most, if not all, body fluid compartments. ${ }^{7}$ A reference is cited, suggesting dissociation between body weight and body water losses during exercise and that total body water may be maintained despite significant reductions in body weight during exercise. In fact, this reference (which is a proceedings poster abstract) is based on an ultraendurance exercise lasting more than 10 hours, suggesting that not all body weight loss during exercise can be attributed to body fluid losses. This finding is correct and has also been demonstrated by other investigators; however, it does not dissociate the 2 variables. Of note, in our study, we observed a reduction in plasma volume by $2.5 \%$ in sodium-free trials, despite the fact that body water during our trials was maintained at baseline values.

We hope that the aforementioned explanations have clarified any confusion that your letter might have caused to the interested $J A T$ readers. We also hope that athletes will keep doing their best by controlling their hydration status and avoiding excessive dehydration, as suggested by the entire body of evidence in the field and outlined in the current recommendations for exercising individuals. ${ }^{3}$

Stavros A. Kavouras, PhD

Costas A. Anastasiou, PhD

Giannis Arnaoutis, MS

Laboratory of Nutrition and Clinical Dietetics

Harokopio University

Athens, Greece

\section{REFERENCES}

1. IOC consensus statement on sports nutrition 2003. J Sports Sci. 2004;22(1):x.

2. Casa DJ, Armstrong LE, Hillman SK, et al. National Athletic Trainers' Association position statement: fluid replacement for athletes. J Athl Train. 2000;35(2):212-224.

3. American College of Sports Medicine, Sawka MN, Burke LM, et al. American College of Sports Medicine position stand: exercise and fluid replacement. Med Sci Sports Exerc. 2007;39(2):377-390.

4. Armstrong LE, Costill DL, Fink WJ. Influence of diuretic-induced dehydration on competitive running performance. Med Sci Sports Exerc. 1985;17(4):456-461.

5. Walsh RM, Noakes TD, Hawley JA, Dennis SC. Impaired highintensity cycling performance time at low levels of dehydration. Int J Sports Med. 1994;15(7):392-398.

6. Maxwell NS, Gardner F, Nimmo MA. Intermittent running: muscle metabolism in the heat and effect of hypohydration. Med Sci Sports Exerc. 1999;31(5):675-683.

7. Maughan RJ, Shirreffs SM, Leiper JB. Errors in the estimation of hydration status from changes in body mass. $J$ Sports Sci. 2007;25(7):797-804. 